\title{
EXPERIMENTAL MEASUREMENTS OF THE WATER EVAPORATION RATE OF A PHYSICAL MODEL
}

Róbert TURZA' ${ }^{1}$, Belo B. FÜRI*2

\section{Abstract}

As the number of indoor swimming pools and wellness centers are currently growing, it is necessary to concentrate on the parameters of indoor environments. These parameters are necessary for the design of the HVAC systems that operate these premises. In indoor swimming-pool facilities, the energy demand is large due to ventilation losses from exhaust air. Since water evaporates from a pool's surface, exhaust air has a high water content and specific enthalpy. In this paper the results of the water evaporation rate measured from swimming pool surfaces at higher thermal water temperatures are described.

\section{Address}

1 Department of Building Services, Faculty of Civil Engineering Slovak University of Technology in Bratislava, Radlinského 11, 81368 Bratislava, Slovakia (robert.turza@ stuba.sk)

2 Department of Building Services, Faculty of Civil Engineering, Slovak University of Technology in Bratislava, Radlinského 11, 81368 Bratislava, Slovakia (belo.furi@stuba.sk)

* Corresponding author: belo.furi@stuba.sk

\section{Key words}

- Evaporation,

- Swimming pool,

- Physical model.

\section{INTRODUCTION}

This paper deals with the topic of the hygro-thermal climate in indoor swimming pools. Ventilation in these places mainly ensures hygienic functions. A ventilation device provides an internal environment for people to feel comfortable in a swimming pool, protects their health by eliminating pollutants, and finally keeps the technology running and protects the building structure. Indoor swimming pools belong among premises with a high moisture production, respectively water vapor, where the relative humidity in this area is usually between 60 to $80 \%$ and in rare cases, even more.

The water temperature depends on the type of pool. In Tab. 1, the water temperatures designated for different pool types are described. The water temperature affects the heat and mass transfer between the water and the human body. Because of the evaporation of water film on an unclothed body, additional heat is lost. Therefore, to minimise the feeling of being cold, the air temperature should be $2 \mathrm{~K}$ to $4 \mathrm{~K}$, minimally $1^{\circ} \mathrm{C}$ according to (Statement 259/2008) above the water temperature, but not above $34{ }^{\circ} \mathrm{C}$ (VDI 2089; Statement 72/2008). The relative humidity in an indoor swimming pool should be within a range of $40 \div 65 \%$. The air flow velocity in the area should be below $0.20 \mathrm{~m} / \mathrm{s}$.
Tab. 1 Water temperatures at an indoor swimming pool

\begin{tabular}{|l|c|c|}
\hline Basin & $\begin{array}{c}\text { Water temperature } \\
\text { according to edict } \\
72 / 2008[5]\left({ }^{\circ} \mathrm{C}\right)\end{array}$ & $\begin{array}{c}\text { Water temperature } \\
\text { according to VDI } \\
2089[4]\left({ }^{\circ} \mathrm{C}\right)\end{array}$ \\
\hline swimming & $18 \div 26$ & 28 \\
\hline non-swimming & 28 & 28 \\
\hline relaxation & 40 & 36 \\
\hline $\begin{array}{l}\text { children up to 36 months } \\
\text { children older 36 months }\end{array}$ & $30 \div 36$ & 32 \\
\hline
\end{tabular}

Water evaporation is a natural process and is a critical energy parameter in a pool's design and control system. Forecasting the evaporation of water from swimming pools according to reliable calculations is required for the accurate projection of HVAC systems. In order to eliminate condensation on cold surfaces in a swimming pool, water vapor has to be removed by a HVAC system; on the other hand, water in a pool has to be heated to compensate for the heat lost by evaporation. Seventy percent of the energy loss in swimming pools comes from water evaporation. 
Water evaporation occurs as a result of a heat transfer between water and the ambient air, and this process cools down the water. Water is evaporated at a temperature lower than the temperature of boiling by the pressure of the ambient air. In this process the pressure from the saturated steam at the water's surface is higher than the partial pressure from the steam in the core of the ambient air. At the same time, the rule is the higher the water temperature, the more intensive the evaporation. The evaporation process that occurs from the contact between the air and a wet surface involves heat and a mass transfer. Therefore, in technical practice mass and heat flow between the air and wet surfaces must be determined (Ferstl, Masaryk 2011). $\Phi_{\mathrm{wl}}$ :

The thermal load from moisture produced by human bodies (hb)

$$
\Phi_{w h b}=m_{w h b} \cdot l_{v 0}=n \cdot m_{h b} \cdot l_{v 0} \quad(W)
$$

where $n$-amount of human bodies (-),

$m_{h b}-$ moisture production from one person, (g/h) (see Tab. 2$)$,

$l_{v 0}$ - latent heat of water at $0{ }^{\circ} \mathrm{C}(\mathrm{J} / \mathrm{kg})$.

Tab. 2 Vapour produced from human bodies according to different activities (Solař, 2010)

\begin{tabular}{|l|l|}
\hline light activity & $30-60 \mathrm{~g} / \mathrm{h}$ \\
\hline medium activity & $120-200 \mathrm{~g} / \mathrm{h}$ \\
\hline heavy activity & $200-300 \mathrm{~g} / \mathrm{h}$ \\
\hline
\end{tabular}

Thermal load from water evaporation $\Phi_{\text {wo }}$ :

$$
\Phi_{w o}=m_{w} \cdot l_{v 0} \quad(W)
$$

where $\mathrm{m}_{\mathrm{w}}$ - amount of evaporated water $(\mathrm{kg} / \mathrm{s})$,

$1_{\mathrm{v} 0}$ - latent heat at $0{ }^{\circ} \mathrm{C}(\mathrm{J} / \mathrm{kg})$.

Amount of evaporated water $\mathrm{m}_{\mathrm{w}}$ (Ferstl, Masaryk, 2011):

$$
\begin{aligned}
m_{w} & =\beta_{p} \cdot A_{w} \cdot\left(p_{p(\theta w)}^{\prime \prime}-p_{p(\theta i)}\right)(\mathrm{kg} / \mathrm{s}) \\
\text { or } \quad m_{w} & =\frac{\beta}{R \cdot T} \cdot A_{w} \cdot\left(p_{p\left(\theta_{w}\right)}^{\prime \prime}-p_{p(\theta i)}\right)(\mathrm{kg} / \mathrm{s})
\end{aligned}
$$

where

$\beta_{p}-$ water transfer coefficient based on the difference in vapor pressures above the water's surface and the ambient air $\left(\mathrm{kg} /\left(\mathrm{m}^{2} . \mathrm{s} . \mathrm{Pa}\right)\right)$,

$\beta-$ the mass transfer coefficient $(\mathrm{m} / \mathrm{h})$,

$\mathrm{R}$ - gas constant for water vapor $(\mathrm{J} /(\mathrm{kg} \cdot \mathrm{K}))$,

$\mathrm{T}-$ arithmetic mean temperature of water and air temperature (K),

$A_{w}-$ water surface area $\left(\mathrm{m}^{2}\right)$,

$\mathrm{p}^{\mathrm{c}(\mathrm{v}(\theta \mathrm{w})}$ - saturated steam partial pressure at water temperature $(\mathrm{Pa})$,

$\mathrm{p}_{\mathrm{v}(\mathrm{ii})}$ - vapor partial pressure at ambient air temperature $(\mathrm{Pa})$.

Due its complex and stochastic nature, the evaporation rate is nearly impossible to predict. In the literature wide variations in the correlations for predicting water evaporation and energy consumption are available ((Sartori, 2000; Shah 2011; Wu, J.Y.et al., 2011). These are considered to be lower water temperatures than thermal waters.

To calculate the coefficient of the evaporation of moisture transfer between the water and the ambient air, equations such as the
Sherwood criterion Sh are used:

$$
S h=\frac{\beta_{p} \cdot L}{D_{p, P}} \quad(-)
$$

where

$\beta_{p}-$ water transfer coefficient based on the difference in vapor pressures above the water's surface and ambient air $\left(\mathrm{kg} /\left(\mathrm{m}^{2} . \mathrm{s} . \mathrm{Pa}\right)\right)$,

L - characteristic dimension - length in the air flow direction (m),

$\mathrm{D}_{\mathrm{p}, \mathrm{P}}$ - pressure dependence of diffusion coefficient based on the difference of partial pressures $(\mathrm{kg} /(\mathrm{m} . \mathrm{s} . \mathrm{Pa}))$.

In a case where the water level is below the edge of a swimming pool, the Sherwood criterion must be modified by a correction factor, which includes the effect of a reduced level of humidity transfer. In that case the Sherwood criterion Sh is given by:

$$
\begin{gathered}
S h=\frac{\beta_{p} \cdot L}{D_{p, P} \cdot H^{1 / 4}} \quad(-) \\
H=1+\frac{\Delta H}{L} \quad(-)
\end{gathered}
$$

where

$\Delta \mathrm{H}-$ vertical distance of the tank and water level (m),

The Sherwood criterion is a function of other criteria, such as the Reynolds, Archimedes and Schmidt criteria. The Schmidt criterion Sc characterizes the similarity of the physical properties of moist air. The Reynolds criterion Re, Archimedes criterion Ar, and Schmidt criterion Sc are independent variables and determine the Sherwood criterion $\mathrm{Sh}$ in the following expression:

$$
S h=C \cdot \operatorname{Re}^{a} \cdot A r^{b} \cdot S c^{d} \quad(-)
$$

where

Re - Reynolds criterion,

Ar - Archimedes criterion,

Sc - Schmidt criterion.

The individual criteria of hydrodynamic similarity relations can be expressed as:

$$
\begin{gathered}
\operatorname{Re}=\frac{v \cdot L}{v_{v}} \quad(-) \\
A r=\frac{g \cdot L^{3}}{v_{v}^{2}} \cdot \frac{\rho_{s}^{\prime \prime}-\rho_{i}}{\rho_{s}^{\prime \prime}} \quad(-) \\
S c=\frac{v_{v}}{D_{c}}(-)
\end{gathered}
$$

where

$\mathrm{V}$ - speed of the air above the water's surface $(\mathrm{m} / \mathrm{s})$,

$\mathrm{L}$ - characteristic dimension - length in direction of the air flow (m),

$v_{v}$ - mean kinematic viscosity at determining temperature $\theta_{u}$ $\left(\mathrm{m}^{2} / \mathrm{s}\right)$,

g - acceleration of gravity $\left(\mathrm{m} / \mathrm{s}^{2}\right)$,

$\rho^{\text {“ }}{ }_{\mathrm{s}}$ - density of saturated air above the water's surface at a temperature of water $\theta_{\mathrm{s}}\left(\mathrm{kg} / \mathrm{m}^{3}\right)$,

$\rho_{\mathrm{i}}$ - density of ambient air above the water's surface at the temperature $\theta \mathrm{i}\left(\mathrm{kg} / \mathrm{m}^{3}\right)$,

D - diffusion coefficient relating to the difference in the concentration $\left(\mathrm{m}^{2} / \mathrm{s}\right)$. 
Based on the air and water conditions measured and the weight loss from the water tank, we were able to determine the water transfer coefficient.

\section{EXPERIMENTAL MEASUREMENTS}

One way of determining the mass flow of evaporated water, respectively, the water transfer coefficient, is an experimental measurement.

The physical model used for measuring water evaporation (Fig. 1) consists of:

- A test chamber of the internal environment of a swimming pool (plexiglas, polystyrene),

- measuring devices for measuring weight, temperature, specific humidity, and air velocity,

- inner container with built-in water heating with a volume of 12 liters,
- water basin surface $A=0.3 \times 0.33 \mathrm{~m}=0.099 \mathrm{~m}^{2}$,

- temperature and air flow (velocity) control.

The water temperature, the air temperature and its velocity were regulated in the physical model of the indoor swimming pool in the laboratory. Based on the water temperature, air temperature is then determined; the values should be higher than that of the water, but not higher than $34{ }^{\circ} \mathrm{C}$. The air flow velocity in an indoor swimming pool should be maximally $\mathrm{v}=0.20 \mathrm{~m} / \mathrm{s}$ for sufficient ventilation; the air velocity should minimally be $\mathrm{v}=0.10 \mathrm{~m} / \mathrm{s}$. For these reasons, these three air flow velocities were selected for further investigation. For the different values of these parameters, measurements of the evaporated water mass were made. The loss of water weight in the modeled water basin was measured with a weighting machine.

Measurements of the preset values (water temperature, air temperature and velocity) were taken for 1 hour (60 minutes). Individual measurements were carried out after stabilization of the values (about $15 \div 30 \mathrm{~min}$.). The individual measurements were repeated to confirm the results.

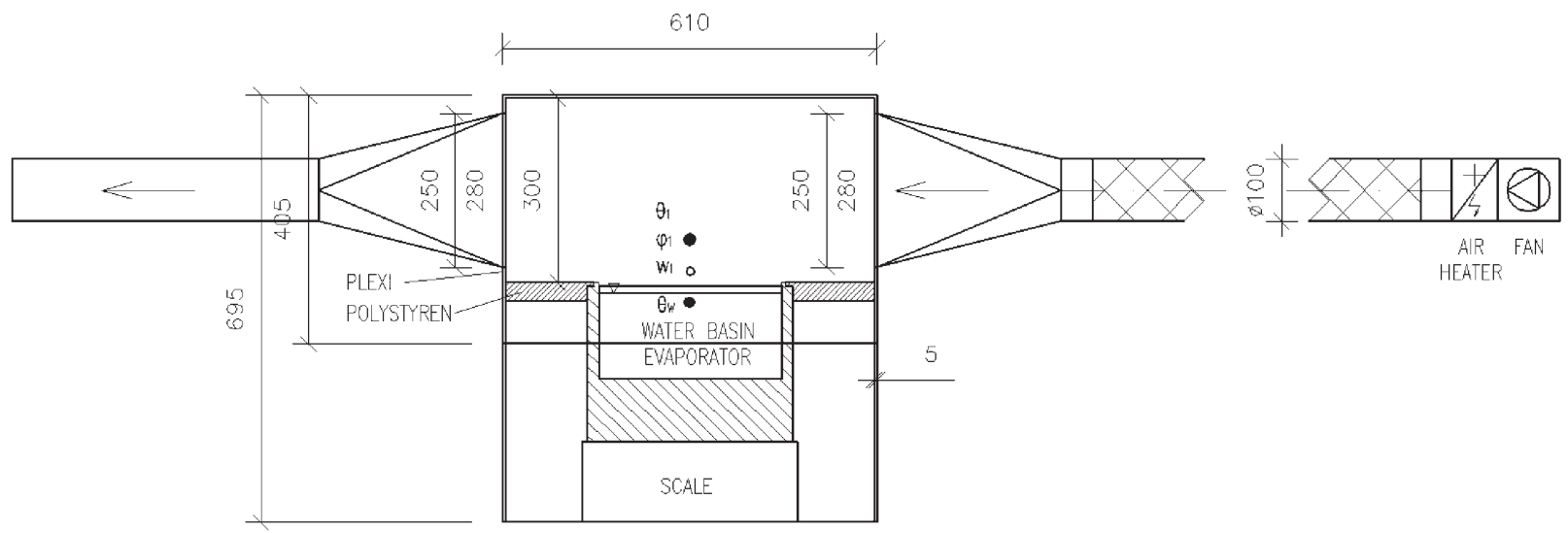

Fig. 1 Layout of the physical model of an indoor swimming pool

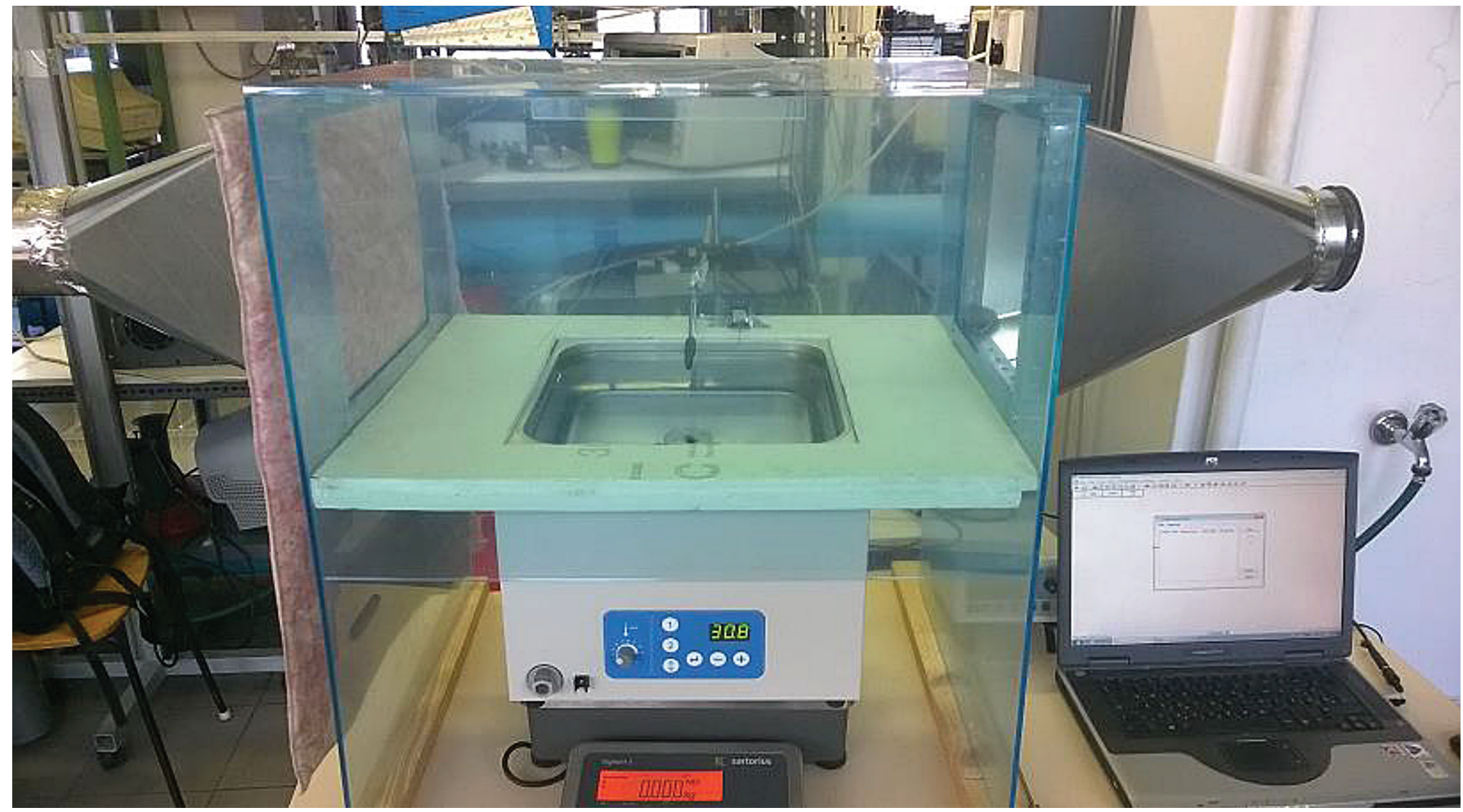

Fig. 2 The physical model of an indoor swimming pool 


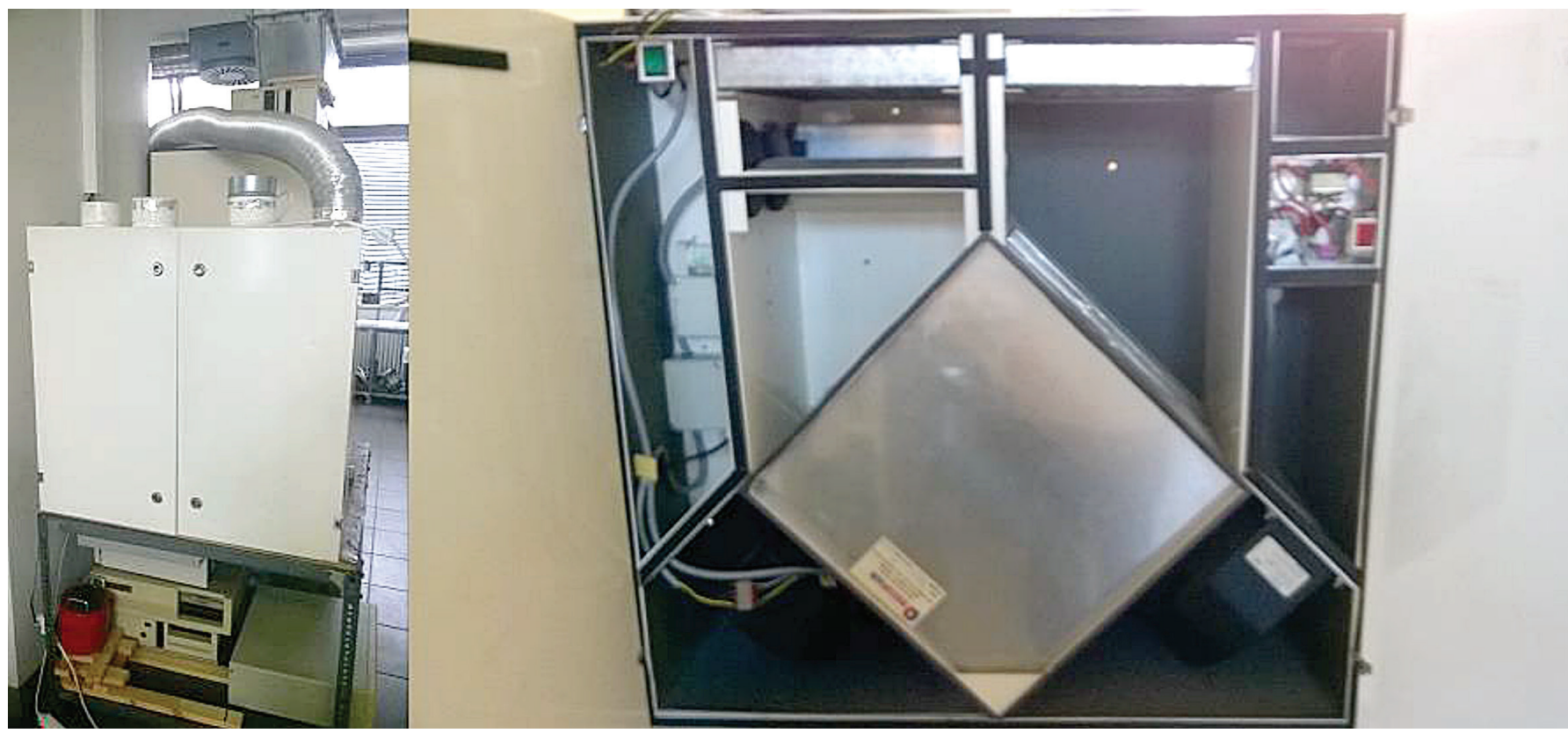

Fig. 3 Air handling unit

From the correlations of the evaporated water mass flow, we can determine from equation (3) the formula for calculating the water transfer coefficient based on the difference in the specific humidity $\beta_{\mathrm{x}}$ :

$\dot{m}_{w}=\beta_{x} \cdot\left(x_{w}-x_{i}\right)=\frac{\Delta m}{A_{w} \cdot \tau} \Rightarrow \beta_{x}=\frac{\Delta m}{\left(x_{w}-x_{i}\right) \cdot A_{w} \cdot \tau} \quad\left(\mathrm{kg} /\left(\mathrm{m}^{2} \cdot \mathrm{h}\right)\right)$

Or, we can use equation (4) to calculate the water transfer coefficient based on partial pressure difference $\beta_{p}$

$\dot{m}_{w}=\beta_{p} \cdot\left(p_{p w}^{\prime \prime}-p_{p i}\right)=\frac{\Delta m}{A_{w} \cdot \tau} \Rightarrow \beta_{p}=\frac{\Delta m}{\left(p_{p w}^{\prime \prime}-p_{p i}\right) \cdot A_{w} \cdot \tau} \quad\left(\mathrm{kg} /\left(\mathrm{m}^{2} \cdot \mathrm{h}\right)\right)$

\section{RESULTS}

The mass flow of the evaporated water was determined from the measurements of the physical model. Processing the measurements was conducted on the basis of the mean values of the individual measurements. These values were also used for a further evaluation.

The mean value of the measured mass flow rate of the evaporated water at the airflow velocity $\mathrm{v}=0.10 \mathrm{~m} / \mathrm{s}$ was $\Delta \mathrm{m}_{0.10}=19.60 \mathrm{~g} / \mathrm{h}$.

The mean value of the measured mass flow rate of the evaporated water at the airflow velocity $\mathrm{v}=0.15 \mathrm{~m} / \mathrm{s}$ was $\Delta \mathrm{m}_{0.15}=20.20 \mathrm{~g} / \mathrm{h}$.

The mean value of the measured mass flow rate of the evaporated water at the airflow velocity $\mathrm{v}=0.20 \mathrm{~m} / \mathrm{s}$ was $\Delta \mathrm{m}_{0.20}=22.10 \mathrm{~g} / \mathrm{h}$.

The average value of the water transfer coefficient, based on the specific moisture difference calculated from the measurements, according to equation (12) at the airflow velocity $\mathrm{v}=0.10 \mathrm{~m} / \mathrm{s}$, was $\beta_{\mathrm{x}, 0,10}=9,20.10^{-3}\left(\mathrm{~kg} / \mathrm{m}^{2} . \mathrm{h}\right)$.

The average value of the water transfer coefficient based on the specific moisture difference calculated from the measurements, according to equation (12) at the airflow velocity $\mathrm{v}=0.15 \mathrm{~m} / \mathrm{s}$, was $\beta_{\mathrm{x}, 0.15}=9,60.10^{-3}\left(\mathrm{~kg} / \mathrm{m}^{2} . \mathrm{h}\right)$.

The average value of the water transfer coefficient, based on the specific moisture difference calculated from the measurements, according to equation (12) at the airflow velocity $\mathrm{v}=0.20 \mathrm{~m} / \mathrm{s}$, was $\beta_{\mathrm{x}, 0.20}=10,00.10^{-3}\left(\mathrm{~kg} / \mathrm{m}^{2} . \mathrm{h}\right)$.
The average value of the coefficient of the water transfer, based on the partial pressure difference calculated from the measurements, according to equation (13) at the airflow speed $\mathrm{v}=0.10 \mathrm{~m} / \mathrm{s}$, was $\beta_{\mathrm{p}, 0,10}$ $=6,10 \cdot 10^{-5} \mathrm{~kg} /\left(\mathrm{m}^{2} . h \cdot P a\right)$.

The average value of the coefficient of water transfer based on the partial pressure difference calculated from the measurements, according to equation (13) at the airflow speed $\mathrm{v}=0.15 \mathrm{~m} / \mathrm{s}$, was $\beta_{\mathrm{p}, 0,10}=6,30.10^{-5} \mathrm{~kg} /\left(\mathrm{m}^{2}\right.$.h.Pa $)$.

The average value of the coefficient of water transfer based on the partial pressure difference calculated from the measurements, according to the equation (13) at the airflow speed $\mathrm{v}=0.20 \mathrm{~m} / \mathrm{s}$, was $\beta_{\mathrm{p}, 0,20}=6,60 \cdot 10^{-5} \mathrm{~kg} /\left(\mathrm{m}^{2}\right.$.h.Pa $)$.

From the above it is clear that the value of the water transfer coefficients increases with an increasing air flow velocity, i.e., an increasing air pressure dynamic.

To calculate the water transfer coefficient between the water surface and ambient air, we used criteria relations such as the Sherwood criterion $S_{h}$. In this case where the Reynolds number was $\operatorname{Re}<5.10^{5}$, we used the following equation (Turza, 2015):

$$
S h=\frac{\beta_{x} \cdot L}{D_{p P}}=0.322 x \operatorname{Re}^{1 / 2} \times S c^{1 / 3}
$$

The results of these calculations are in Tab. 3, where $\beta_{x}$ stands for the water transfer coefficient based on the difference in specific humidity, $\beta_{\mathrm{p}}$ on the partial pressure difference, $\beta_{\mathrm{m}}$ on the calculated water transfer coefficient of the physical model according to the criterial relations, and $\beta_{\mathrm{n}}$ is the normative value.

Tab. 3 Measured water transfer coefficients

\begin{tabular}{|l|l|l|l|}
\hline \multirow{2}{*}{$\begin{array}{l}\text { Water transfer } \\
\text { coefficient }\end{array}$} & \multicolumn{3}{|c|}{$\mathrm{v}(\mathrm{m} / \mathrm{s})$} \\
\cline { 2 - 4 } & 0.10 & 0.15 & 0.20 \\
\hline$\beta_{\mathrm{x}} \cdot 10^{3}\left(\mathrm{~kg} /\left(\mathrm{m}^{2} . \mathrm{h}\right)\right)$ & 9.19 & 9.58 & 10.03 \\
\hline$\beta_{\mathrm{p}} \cdot 10^{5}\left(\mathrm{~kg} /\left(\mathrm{m}^{2} . \mathrm{h} \cdot \mathrm{Pa}\right)\right)$ & 6.08 & 6.34 & 6.63 \\
\hline$\beta_{\mathrm{m}}(\mathrm{m} / \mathrm{h})$ & 4.00 & 4.83 & 5.55 \\
\hline$\beta_{\mathrm{n}}(\mathrm{m} / \mathrm{h})$ & - & - & 7.00 \\
\hline
\end{tabular}


The diagram in Fig. 4 shows the values of the weight loss measured from the water tank $\mathrm{Dm}(\mathrm{g} / \mathrm{h})$ by different settings of the airflow velocity $\mathrm{v}$, water $\theta_{\mathrm{w}}$, and air temperature $\theta_{\mathrm{i}}$ in the swimming pool.

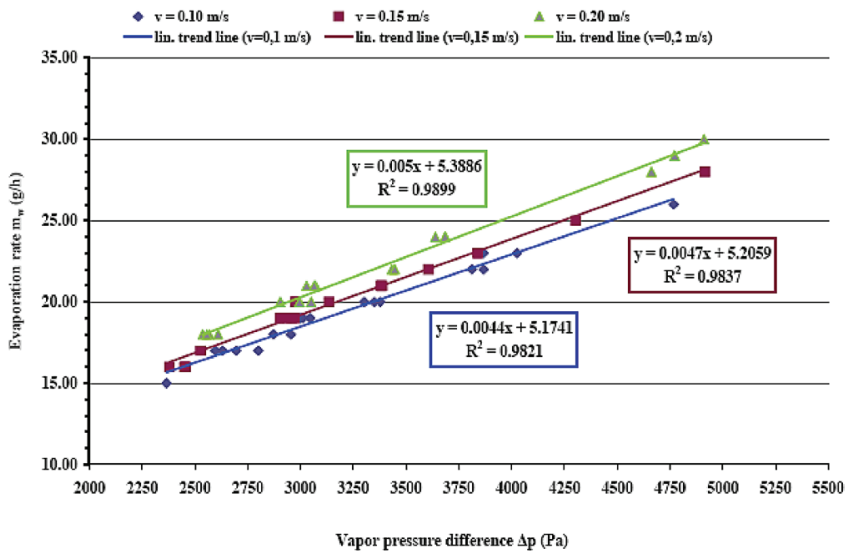

Fig. 4 Water loss according to the difference in vapour pressure and airflow velocity

The diagram in Fig. 5 shows from the experimental measurements, the calculated evaporation coefficients $\beta_{x}\left(\mathrm{~kg} /\left(\mathrm{m}^{2} . \mathrm{h}\right)\right)$, depending on the specific humidity difference $\Delta \mathrm{x}(\mathrm{g} / \mathrm{kg})$ and the trend lines with the correlation factors.

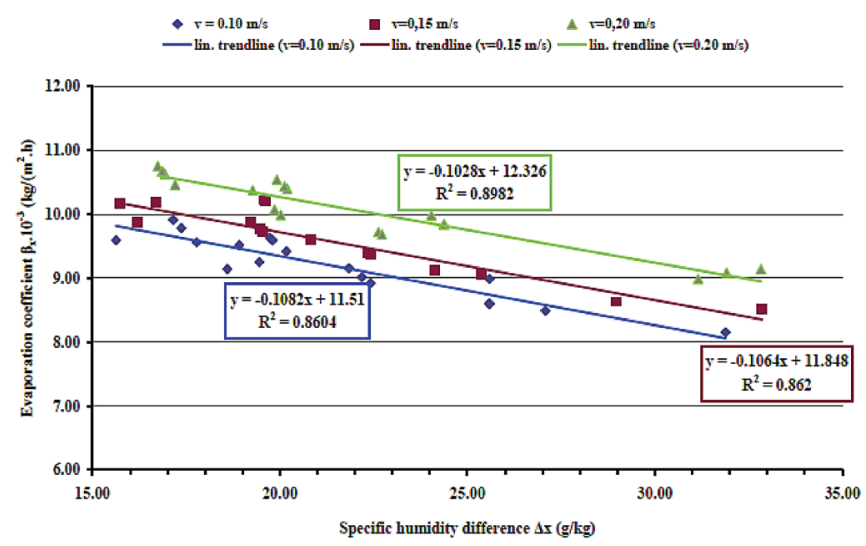

Fig. 5 Coefficient of moisture transfer based on the difference in the specific humidity and airflow velocity
The diagram in Fig. 6 shows from the experimental measurements, the calculated evaporation coefficients $\beta_{x}\left(\mathrm{~kg} /\left(\mathrm{m}^{2} . \mathrm{h}\right)\right)$, depending on the vapour pressure difference $\Delta \mathrm{p}(\mathrm{Pa})$, trend lines, and correlation factors.

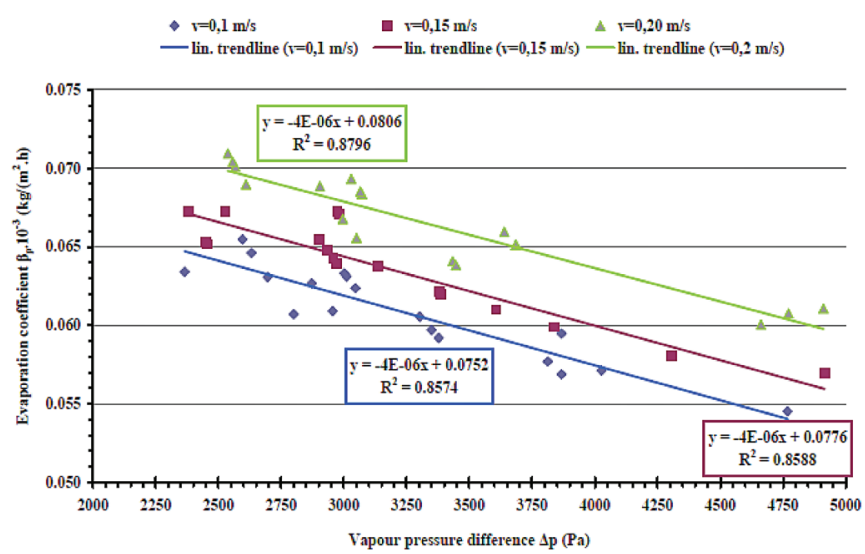

Fig. 6 Coefficient of moisture transfer based on the difference in the vapour pressure and airflow velocity

\section{CONCLUSION}

In this paper the results of the measurements on a physical model were described. To be able to use these results widely in other facilities, adjustments for the water transfer coefficient must be performed. The object of this paper was to conduct measurements on a physical model of an indoor swimming pool. Various inputs of indoor parameters were simulated in laboratory conditions, corresponding to an actual swimming pool, and their impact on the process of evaporation from the water surface at higher thermal water temperatures in the basin.

\section{Acknowledgment}

The physical model of the indoor swimming pool was developed with the help of the Budapest University of Technology and Economics, Faculty of Mechanical Engineering, Department of Building Services and Process Engineering.

\section{REFERENCES}

Asdrubali, F. (2009) $A$ scale model to evaluate water evaporation from indoor swimming pools, Energy and Buildings 41/2009, pp. 311-319

Ferstl, K., Masaryk, M. (2011) Prenos tepla (Heat Transfer), STU, Bratislava, 2011 ISBN 978-80-227-3534-6

Sartori, E. (2000) A critical review on equation employed for the evaporation rate from free water surfaces, Solar Energy 1/2000, pp. $77-89$

Shah, M., (2011) Improved method for calculating evaporation from indoor water pools, Energy and Buildings 49/2011, pp. 306-309

Solař, J. (2010) Řešení problematiky povrchové kondenzace vodni páry (Solution of surface condensation of water vapour), www. tzb-info.cz, 7. 6. 2010
Statement of Slovak Ministry of Health (2008) No.: No.: 72/2008

Statement of Slovak Ministry of Health (2008) No.: 259/2008

Turza, R. (2015) Analysis and design of hot air ventilation and dehumidification systems in covered swimming pools, PhD. Thesis SvF-13422-41300, STU in Bratislava

VDI 2089, Building services in swimming baths - Indoor pools

Wu, J. Y. (2011) Sun, P., Wang, G, R. Z., Xu, Y. X., Analysis of indoor environmental conditions and heat pump energy supply systems in indoor swimming pools, Energy and Buildings 43/2011, pp. 1071-1080 